\title{
Microfabrication of Palladium-Silver Alloy Membranes for Hydrogen Separation
}

\author{
Hien Duy Tong, J. W. Ervin Berenschot, Meint J. De Boer, J. G. E. (Han) Gardeniers, Henk Wensink, Henri V. Jansen, \\ Wietze Nijdam, Miko C. Elwenspoek, F. C. (Frank) Gielens, and Cees J. M. van Rijn
}

\begin{abstract}
In this paper, a process for the microfabrication of a wafer-scale palladium-silver alloy membrane (Pd-Ag) is presented. Pd-Ag alloy films containing 23 wt\% Ag were prepared by co-sputtering from pure Pd and Ag targets. The films were deposited on the unetched side of a $\langle\mathbf{1 1 0}\rangle$-oriented silicon wafer in which deep grooves were etched in a concentrated KOH solution, leaving silicon membranes with a thickness of ca. $50 \mu \mathrm{m}$. After alloy deposition, the silicon membranes were removed by etching, leaving Pd-Ag membranes. Anodic bonding of thick glass plates (containing powder blasted flow channels) to both sides of the silicon substrate was used to package the membranes and create a robust module. The hydrogen permeability of the Pd-Ag membranes was determined to be typically $0.5 \mathrm{~mol} \mathrm{H}_{2} / \mathrm{m}^{2}$. s with a minimal selectivity of 550 for $\mathrm{H}_{2}$ with respect to He. The mechanical strength of the membrane was found to be adequate, pressures of up to 4 bars at room temperature did not break the membrane. The results indicate that the membranes are suitable for application in hydrogen purification or in dehydrogenation reactors. The presented fabrication method allows the development of a module for industrial applications that consists of a stack of a large number of glass/membrane plates.

[901]
\end{abstract}

Index Terms $-\langle 110\rangle$ wafers, co-sputtering membrane module, hydrogen separation, microfabrication technology, palladium-silver (Pd-Ag) membrane.

\section{INTRODUCTION}

$\mathbf{T}$ HE increased demand for hydrogen in recent years in many industrial applications, like petroleum refinement, petrochemical and semiconductor processing and sustainable energy (fuel cells) has led to a revival of interest in methods for separation and purification of hydrogen from gas mixtures [1]-[3]. In particular, palladium (Pd)-based membranes have been the subject of many studies, due largely to their unmatched potential as hydrogen-selective membranes for gas separation or purification. In most cases, palladium is alloyed with silver $(\mathrm{Ag})$ to overcome the well-known problem of hydrogen embrittlement [4], [5]. Comprehensive reviews of Pd-based membranes and their applications have recently been provided by Shu et al. [6] and Dittmeyer et al. [7].

Manuscript received July 10, 2002; revised May 7, 2003. This work was supported by STW (the Dutch Technology Foundation), ABB Lummus Global, Inc., DSM, and Aquamarijn. Subject Editor A. J. Ricco.

H. D. Tong, J. W. E. Berenschot, M. J. De Boer, J. G. E. Gardeniers, H. Wensink, H. V. Jansen, W. Nijdam, and M. C. Elwenspoek are with the MESA + Research Institute, University of Twente, 7500 AE Enschede, The Netherlands (e-mail: T.Hien@el.utwente.nl).

F. C. Gielens is with the Department of Chemical Engineering and Chemistry, Eindhoven University of Technology, 5600 MB Eindhoven, The Netherlands.

C. J. M. van Rijn is with the Aquamarijn Micro Filtration B.V., 7255 DB Hengelo, The Netherlands.

Digital Object Identifier 10.1109/JMEMS.2003.818458
However, conventional technology is limited by the high cost of palladium combined with fabrication methods resulting in thick Pd films. For instance, relatively expensive Pd-Ag multitubular assemblies with a membrane thickness of $50 \mu \mathrm{m}$ or more have been used for many years in the laboratory for the purification of hydrogen [8], [9]. The wall thickness of these tubes incorporated in such assemblies reduces the hydrogen flux and inhibits their application for large-scale chemical production.

During the last decade it was attempted to achieve higher hydrogen fluxes by depositing thin $\mathrm{Pd}$ or $\mathrm{Pd}-\mathrm{Ag}$ films on porous supports [10]-[12]. However, the selectivity of such membranes is often poor due to the fact that the used deposition method render insufficient step coverage, i.e., the inner walls of the pores of the support are not well covered by the film [10]-[12], leading to pin-holes in the membranes that give rise to gas leakage.

Recently it was demonstrated that methods originating from the field of microfabrication technology offer a novel approach for the fabrication of very thin, pin-hole free Pd-composite membranes [13], [14]. Such thin films dramatically increase the achievable hydrogen flux as well as the selectivity of the membrane, and possibly decreasing the costs, if the batch fabrication possibilities of microfabrication technology can be exploited. For example, a microfabricated Pd membrane reported by Frank et al. [13] achieved a high flux and high selectivity and is suitable for hydrogen purification in the laboratory, where normally a small, high quality amount of hydrogen is required.

However, most of the microfabricated Pd membranes reported up to now only have a limited size. Such micro units [13], [14] are unsuitable for the separation of high volumes of hydrogen. Furthermore, the reported micromachined Pd membranes were packaged with a PDMS polymer, which does not survive the high temperatures that are applied in industrial hydrogen separation, where hydrogen is normally extracted from a synthesis gas (a mixture of $\mathrm{CO}$ and $\mathrm{H}_{2}$ ) at temperatures above about $400{ }^{\circ} \mathrm{C}$. The study presented in this paper focuses on the fabrication of a wafer-scale micromachined separation membrane module-macro unit, which is suitable for larger volume hydrogen separation in industry. The performance with respect to mechanical strength, hydrogen flux and selectivity of the $\mathrm{Pd}-\mathrm{Ag}$ membranes in such a module was characterized and will be discussed in detail in this paper.

\section{FAbrication of the MEMbrane Module}

\section{A. Pd-Ag Membranes on a Silicon Frame}

A cross section of the $\mathrm{Pd}-\mathrm{Ag}$ membrane module is shown in Fig. 1. It consists of a silicon wafer and two glass wafers. The 


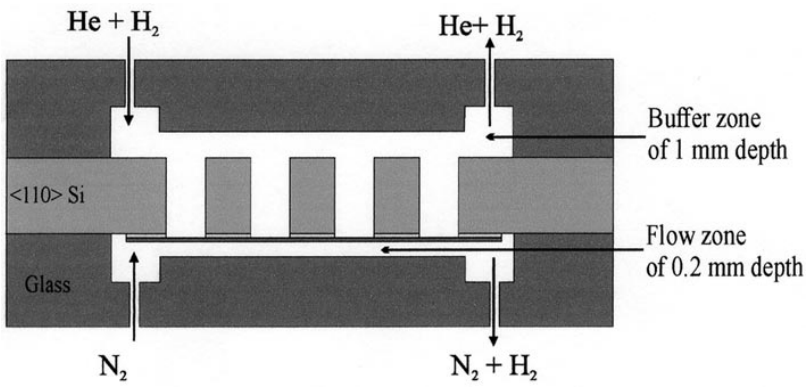

Fig. 1. Cross section of the separation membrane module.

$<111>$ direction finding, opening slits on front side

$<110>\mathrm{Si}$

$\mathrm{KOH}$ etching

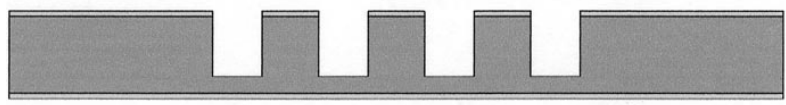

Sputtering of $1 \mu \mathrm{m}$ Pd-Ag/Ti

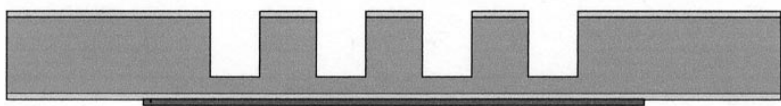

$\mathrm{KOH}$ etching, removing $\mathrm{SiO}_{2}$ and $\mathrm{Ti}$

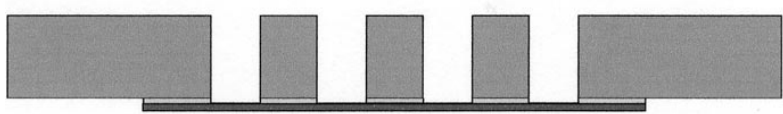

Anodic bonding with thick glass

Fig. 2. Fabrication process of the $\mathrm{Pd}-\mathrm{Ag}$ membrane

sequence of process steps that was applied to achieve the membrane module is outlined in Fig. 2. In brief, the sequence runs as follows: A 3 inch double-side polished, $\langle 110\rangle$-oriented silicon wafer $(\langle 110\rangle-\mathrm{Si})$ is coated with 1 ìm of wet-thermally oxidized silicon dioxide $\left(\mathrm{SiO}_{2}\right)$, which is used as a protective layer during subsequent etching steps. To fabricate high-aspect-ratio features by anisotropic etching of $\langle 110\rangle-\mathrm{Si}$, precise alignment of the features to the $\{111\}$ planes is of critical importance. To reveal the $\{111\}$ planes in the $\langle 110\rangle-\mathrm{Si}$, fan-shaped structures are first imprinted on the silicon wafer by standard photolithography, followed by removal of $\mathrm{SiO}_{2}$ in a commercial buffered oxide etch (BOE), and a short etch in a concentrated $\mathrm{KOH}$ solution. More details can be found in refs. [15], [16]. Next, long narrow slits of 23 by $1500 \mu \mathrm{m}$ are aligned to the revealed $\{111\}$ planes and lithographically patterned using the steps mentioned above. The design consists of 1000 of such slits, which are divided into 8 ranges on a square area of 18 by $18 \mathrm{~mm}$. The wafer is immersed in $25 \% \mathrm{KOH}$ solution at $75^{\circ} \mathrm{C}$ to etch the silicon until about $50 \mu \mathrm{m}$ of silicon is left at the bottom of the etched slits. As a result, etched structure or a silicon frame is created and shown in Fig. 3.

At this stage, an alloy film of Pd77-Ag23 at wt\% with a thickness of $1 \mu \mathrm{m}$ is deposited by co-sputtering [17] through a shadow mask on the flat side of the etched silicon frame, using titanium (Ti) as an adhesion layer. The co-sputtering pro-

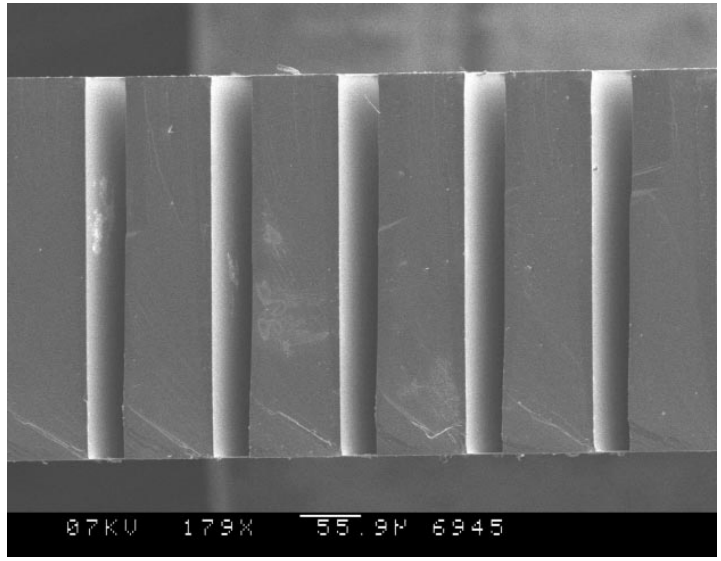

Fig. 3. SEM pictures of the silicon frame, narrow slits were etched in the $\langle 110\rangle$-oriented silicon wafer.

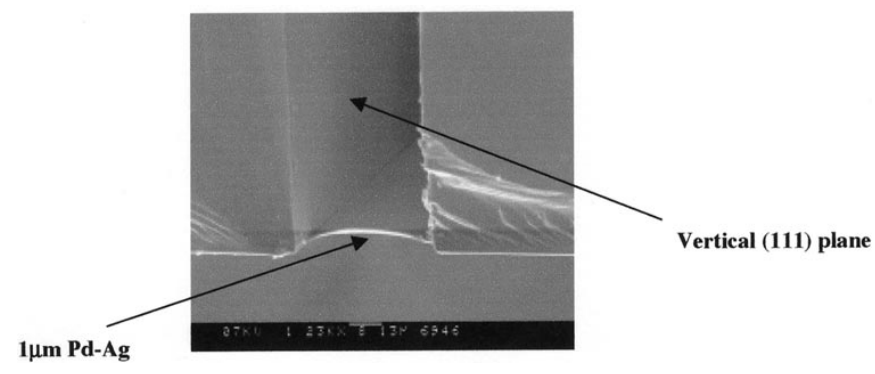

Fig. 4. Close-up of the Pd-Ag membrane across one etched slit.

cedure to deposit a homogenous $\mathrm{Pd}-\mathrm{Ag}$ alloy film will be discussed in detail in Section II-B. Obviously, an advantage of this fabrication method is that $\mathrm{Pd}-\mathrm{Ag}$ film is deposited onto a flat and smooth surface, therewith avoiding possible step coverage problems that may arise during deposition on a porous or patterned substrate. Thus, a very thin $\mathrm{Pd}-\mathrm{Ag}$ film, potentially free of pin-holes will be obtained.

After alloy deposition, the concentrated $\mathrm{KOH}$ solution mentioned above is used to remove the remaining $50 \mu \mathrm{m}$ of silicon in the trenches. Etching in $\mathrm{KOH}$ is continued until the $\mathrm{SiO}_{2}$ layer is reached. Finally, this oxide layer and the Ti film are removed in $\mathrm{BOE}$ to uncover the back surface of the $\mathrm{Pd}-\mathrm{Ag}$ membranes. It should be mentioned here that the BOE removes $\mathrm{T} i$, but does not affect $\mathrm{Pd}, \mathrm{Ag}$ or $\mathrm{Pd}-\mathrm{Ag}$. A close up of the $\mathrm{Pd}-\mathrm{Ag}$ membrane across one etched slit is depicted in Fig. 4, while Fig. 5 shows a top view of an array of long narrow etched slits on the silicon wafer. In Fig. 5, the gray parts are unpatterned silicon, the black areas are oblique $\{111\}$ planes appearing inside the etched slits, and the whitish parts are free $\mathrm{Pd}-\mathrm{Ag}$ areas as seen through the etched slits.

\section{B. Deposition of Pd-Ag Alloy Film by DC Co-Sputtering}

Due to the high accuracy of the deposition rate, sputtering has frequently been used to fabricate micron-thick $\mathrm{Pd}-\mathrm{Ag}$ alloy layers [11], [12]. Mostly, such layers are obtained by sputtering from a single composite target of $\mathrm{Pd}-\mathrm{Ag}$. However, it was found that the sputtered layers have a significantly lower Ag content than the original target, due to short target equilibration times [12], [18]. For instance, Xomeritakis and Lin [18] found a silver concentration of $15 \%$ for a film sputtered from a Pd75-Ag25 at wt $\%$ target. To avoid this compositional control problem, we 


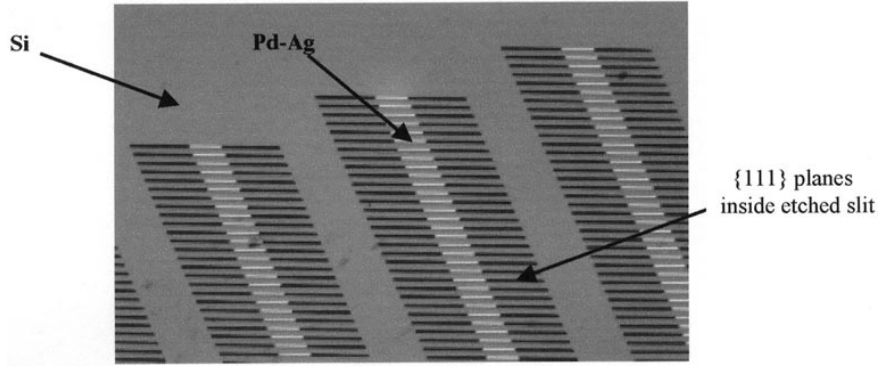

Fig. 5. Top view picture of long narrow etched slits and free areas of $\mathrm{Pd}-\mathrm{Ag}$ on the silicon wafer. The Pd-Ag layer is deposited on the other side of the silicon wafer.

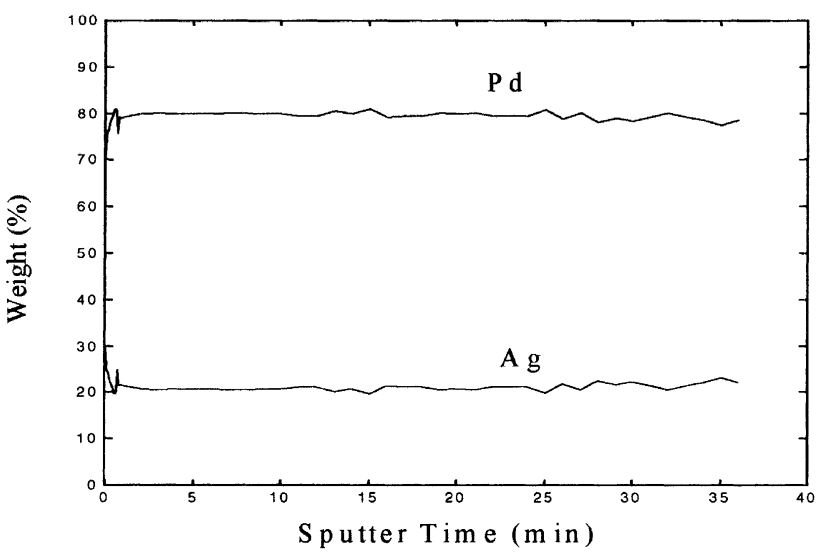

Fig. 6. XPS depth profile of the co-sputtering Pd-Ag film. Ti was detected but it was not show in the graph.

have deposited $\mathrm{Pd}-\mathrm{Ag}$ alloy films by a co-sputtering method using two pure metal targets.

Experiments have been carried out in a dc sputtering system that accommodates three targets, of pure $\mathrm{Pd}, \mathrm{Ag}$, and $\mathrm{Ti}$ ( $\mathrm{Ti}$ is used as an adhesion material), each target having its own controllable power source. Films were deposited at temperatures between $300 \mathrm{~K}$ and $700 \mathrm{~K}$ at an Ar pressure of $5 \cdot 10^{-4} \mathrm{mbar}$. To know the individual sputtered rate of $\mathrm{Pd}$ and $\mathrm{Ag}$ at certain sputtering conditions, several single sputtering runs of Pd and $\mathrm{Ag}$ were done on silicon wafers with photoresist patterns. After sputtering, the resist was removed by acetone in an ultrasonic bath, leaving a patterned metal layer of which the thickness was measured with a Dektak Surface Profiler. From these data, the sputter rate of each metal can be calculated determined. $\mathrm{Pd}-\mathrm{Ag}$ alloy films were achieved by simultaneously sputtering from pure targets of Pd and $\mathrm{Ag}$ on the silicon structure described in the previous section, which contained a $20 \mathrm{~nm}$ thick adhesion layer of Ti sputtered just before. By controlling the power supplied to each target, the sputtered rates were adjusted at 50 and $17 \mathrm{~nm} / \mathrm{min}$ for $\mathrm{Pd}$ and $\mathrm{Ag}$, respectively. If these numbers are converted to weight concentrations, using (bulk) densities of the metals, an alloy composition of Pd77-Ag23 at wt\% is expected. The sputtering time was used to get the desired film thickness, e.g., $15 \mathrm{~min}$ are needed to achieve a $1-\mu \mathrm{m}$-thick alloy film.

The compositions of the $\mathrm{Pd}-\mathrm{Ag}$ alloy films were checked by X-ray Photoelectron Spectroscopy (XPS). A representative example is shown in Fig. 6. It can be seen that the compositions are constant throughout the alloy film, and that the Ag content is just a little lower than expected, which might be due to the fact that the deposition rates of the metals in the co-sputtering

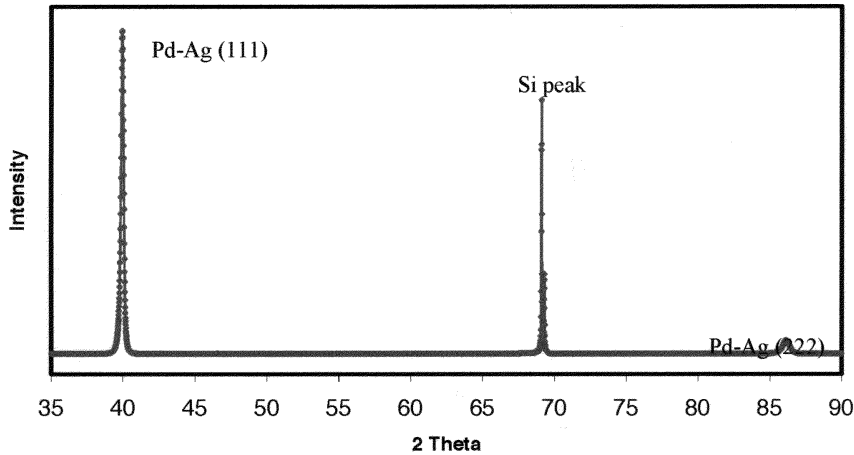

Fig. 7. XRD pattern of the deposited $\mathrm{Pd}-\mathrm{Ag}$ layer on a thin layer of $\mathrm{SiO}_{2}$ on a silicon wafer. The substrate temperature was $400^{\circ} \mathrm{C}$ during sputtering.

state are slightly different from those in the calibration runs in which only one target was used (perhaps due to a slight interference of the plasma fields on the two targets during co-sputtering). Furthermore, using bulk metal densities to calculate the composition of the thin film could also be a reason for the lower $\mathrm{Ag}$ concentration. It has often been reported that, depending on the deposition conditions, the density of sputtered films is lower than that of bulk material [17].

The crystalline properties of the deposited $\mathrm{Pd}-\mathrm{Ag}$ layer were investigated by X-Ray Diffraction (XRD) (Philips, CuKá radiation). The results are shown in Fig. 7. The XRD pattern consists of (111) and (222) diffraction peaks, where the (111) peak corresponds to a lattice spacing of $2.268 \AA$, to be compared with the corresponding $\{111\}$ lattice spacing of pure $\mathrm{Pd}$ and pure $\mathrm{Ag}$ of $2.246 \AA$ and $2.359 \AA$ [18], respectively. The results indicate that the deposited Pd-Ag layer exhibits a preferential orientation in the [111] direction.

The average crystallite size was calculated by applying Scherrer's equation to the (111) peak and found to be about 35 $\mathrm{nm}$, which is quite consistent with the grain size of sputtered $\mathrm{Pd}-\mathrm{Ag}$ layer reported by Xomeritakis et al. [18]. A more detailed XRD study of our sputtered Pd-Ag alloy films will be reported shortly [19].

In conclusion, it was found that an alloy of composition Pd77-Ag 23 at wt\% can be deposited by co-sputtering from separate pure metal targets, which is a powerful method that can be used to fabricate many other types of alloy films with highly accurate compositional control, see also [20].

\section{Flow Channels in Glass by Powder Blasting}

Powder blasting was used to create a flow channel in a $5 \mathrm{~mm}$ thick borosilicate glass wafer. The method consists in directing particles with a high velocity toward a substrate, from which material will be removed by mechanical corrosion. Advantages of the method are: simplicity, low-cost and high etch rate [21]. The process steps used in powder blasting of thick glass plates are outlined in Fig. 8. In brief, two glass wafers were covered with an Ordyl BF 410 photosensitive foil, which acts as a protective layer during powder blasting. After a photolithography process as described in [21], powder blasting was applied to obtain a 1-mm-deep gas buffer zone on each of two glass wafers (see Fig. 1). These buffer zones are used to distribute the flow uniformly over the membrane surface. Without them, most of the gas would flow along the center of the membrane, therewith limiting the effective working area of the membrane. A 


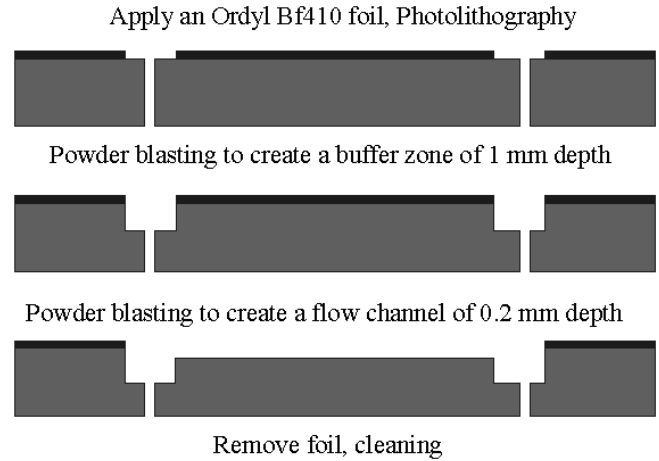

Fig. 8. Process-outline of fabrication of flow channels by powder blasting.

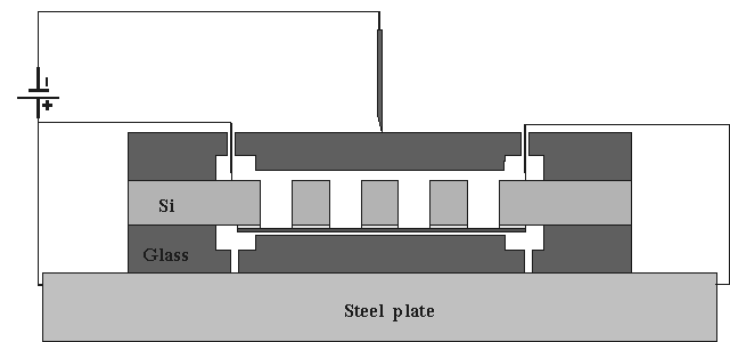

Fig. 9. Four electrode anodic bonding setup for glass-silicon-glass packaging.

second powder blasting step is performed in order to create a 0.2-mm-deep flow channel, which is connected to the peripheral equipment via holes previously drilled in the glass wafers.

\section{Assembly of the Membrane}

In the last process step, the silicon wafer is bonded between the two thick glass wafers by a four-electrode anodic bonding technique (see Fig. 9). This process is performed in two steps, because adequate bonding requires that a positive electrical voltage has to be applied to the silicon and a negative voltage to the glass. The process resulted in a tight seal between each glass wafer and the silicon wafer. Furthermore, the bonding process as it was performed here creates a membrane module which is robust enough for practical use, e.g., in this form it could be integrated in a stainless steel membrane holder (see Fig. 10) to have connections to a gas manifold and analysis equipment. In the used membrane holder, high forces, exerted by screws, are needed to press membrane module and stainless steel plates tightly together, without leakage. In our set-up, flexible graphite rings were applied in between the holder and the membrane module to make a gas-tight connection.

Although not tested here, the bonding method discussed above would allow the construction of a stack that consists of a large number of silicon wafers separated by glass plates. Such a stack would be suitable for industrial applications where a high volume of hydrogen needs to be extracted from a gas mixture.

\section{RESULTS AND DISCUSSION}

\section{A. Etching of $\langle 110\rangle$ Silicon}

Fig. 4 shows a SEM micrograph of the cross-section of several narrow parallel slits, etched in a $350 \mu \mathrm{m}$ thick $\langle 110\rangle$-Si and having a periodicity of $90 \mu \mathrm{m}$. A similar pattern might also be obtained with Deep Reactive Ion Etching (DRIE) [22], however, with that method only one wafer at the time can be pro-

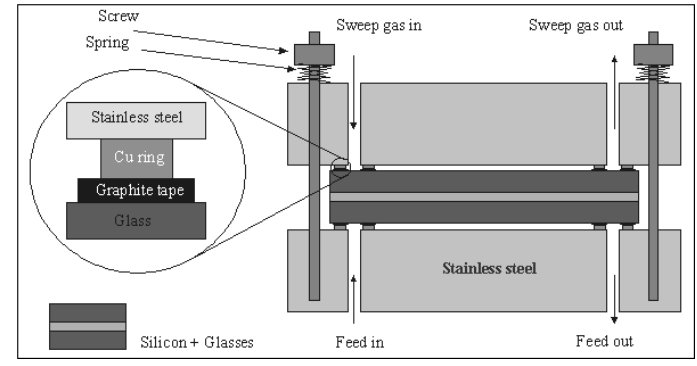

Fig. 10. Membrane holder, the upper part can move up and down and is pressed to the lower part by screws and springs.

cessed, while $\mathrm{KOH}$ etching allows a large number of wafers to be etched simultaneously. More details on high-aspect-ratio etching in $\langle 110\rangle$-Si wafers can be found elsewhere [23]-[26].

From Fig. 4 the width $(l)$ of the etched slit is estimated to be about $28 \mu \mathrm{m}$, while its initial width was defined by lithography to be $23 \mu \mathrm{m}$. This widening of the etched slit should be characterized exactly and taken into account during the design, for two main reasons: 1) a wider slit would imply a wider membrane, which would have a lower mechanical strength (membrane strength strongly depends on membrane width [27]) and 2) unexpected widening of the slits would make the determination of the total free membrane area, i.e., the separation area, difficult. Slit widening is due to a nonzero etch rate of the vertical $\{111\}$ formula planes, which depends on the accuracy of alignment of the mask patterns to the $\{111\}$ planes (this factor was reduced to a minimum in our work by using the previously described fan-shaped pattern to find the exact $\{111\}$ planes), but also on etching conditions [25], [26]. In our work, the ratio of the etch rates of the $\{110\}$ to the $\{111\}$ planes is estimated to be about 140, which is comparable to data reported by Holke and Henderson [26].

These data can be used to calculate the substrate porosity, defined here as the relative area of the substrate that is available for hydrogen permeation. To define the hydrogen separation membrane area, the length of the free area $\left(L_{m}\right)$ created by $\mathrm{KOH}$ etching of one slit through a (110) silicon substrate should be known (see Fig. 3). Using simple geometrical considerations, this length $L_{m}$ is given by [23]

$$
L_{m}-L_{s}-2 \sqrt{3} D+\frac{3 \sqrt{2}}{4} l
$$

with $L_{s}$ the length and $l$ the width of the opening slit, and $D$ the thickness of silicon wafer. Applying (1) with $L_{s}=1500 \mu \mathrm{m}$, $D=350 \mu \mathrm{m}$ and $l=28 \mu \mathrm{m}$, gives a length $L_{m}$ of $317 \mu \mathrm{m}$. As a result, etching one slit per area of $1500 \mu \mathrm{m}$ by $90 \mu \mathrm{m}$ through a $\langle 110\rangle$-Si creates an effective separation area of $317 \mu \mathrm{m}$ by 28 $\mu \mathrm{m}$.

In the first study, much attention was directed to exploring the microfabrication technology as a novel method to fabricate thin, strong and pin-hole free membranes to gain high hydrogen permeation and high selectivity, a membrane porosity (an area percentage to allow hydrogen permeation) has not been studied in detail. In the following paragraph, the membrane porosity aspect is discussed.

By making the slit broader (increasing $l$ ) or longer (increasing $L_{s}$ ) or using a thinner wafer [see (1)] will give a larger effective area for hydrogen separation and will increase the porosity. 
However, as will be shown in the next section, the mechanical strength of the membranes strongly depends on their shortest dimension [27], therefore increasing their width $(l)$ will result in weaker membranes. An alternative way to increase the porosity is to decrease the pitch of the slits. Taking all the above into account, the optimized design of the separation module will consist of slits of $3000 \mu \mathrm{m}$ by $23 \mu \mathrm{m}$ with a periodicity of $50 \mu \mathrm{m}$, giving a porosity of about $20 \%$.

The porosity can be increased even further, by using deep-reactive ion etching (DRIE) [22]. DRIE of silicon is not restricted by silicon $\{111\}$ planes and therefore it is possible to achieve slits with $L_{m}=L_{s}$. However, the drawback of using the reactive ion etching method is that wafer throughput is much lower than that obtainable with $\mathrm{KOH}$ etching.

\section{B. Mechanical Strength of the Membranes}

The mechanical strength of the membranes is an important aspect, as the hydrogen flux is driven by a (partial) pressure difference across the membrane. Predicting the mechanical strength of the membranes is however quite complicated, as it depends on various factors like membrane construction, thickness and material properties (which for thin films may be difficult to estimate or measure). Therefore, the strength of membranes is normally determined experimentally. Nevertheless, a rough estimation of the strength is very valuable during the design phase, and therefore we started our work with an estimation of the strength of our microfabricated membranes based on the originally chosen design parameters width and length (defined by the lithographic process), thickness and (bulk) material properties.

As can be seen in Figs. 1 and 5, the microfabricated membrane module is composed of many smaller $\mathrm{Pd}-\mathrm{Ag}$ membranes acting in parallel, of which a single one is formed by a $\mathrm{Pd}-\mathrm{Ag}$ membrane spanning across one etched slit. It can safely be assumed that the mechanical strength of the silicon support that surrounds the $\mathrm{Pd}-\mathrm{Ag}$ membranes is much higher than that of a single $\mathrm{Pd}-\mathrm{Ag}$ membrane, therefore the strength of the whole membrane module will be mainly determined by that of a single membrane. Van Rijn et al. [27] derived an equation that can be used to estimate the maximum transmembrane pressure $P_{\max }$ for a thin membrane of composed of a ductile material

$$
P_{\max }=6.4 \frac{h \sigma_{\text {yield }}^{3 / 2}}{l E^{1 / 2}}
$$

where $h$ is the thickness of the membrane, $l$ the length of the shortest side of the membrane, $\sigma_{\text {yield }}$ the yield stress and $E$ the Young's modulus of the membrane material. Several values of $E$ and $\sigma_{\text {yield }}$ for thick foils of Pd and $\mathrm{Ag}$ are given in Table I [28]. However, the values of $E$ and $\sigma_{\text {yield }}$ for sputtered Pd77-Ag23 wt $\%$ alloy film have not been reported yet. Besides that, the mechanical properties of thin may differ for different deposition methods and conditions [17], so that film property data obtained from literature cannot be taken for granted. Very critical is the temperature at which the membrane will have to operate. In general, both $E$ and $\sigma_{\text {yield }}$ are temperature dependent and typically a higher temperature will lower $\sigma_{\text {yield }}$. If it is assumed that the material properties of an alloy can be interpolated from the properties of the individual metal elements, we arrive at a yield strength of $80 \mathrm{MPa}$ and a Young's modulus of $150 \mathrm{GPa}$
TABLE I

Mechanical Properties of Pd, Ag, AND the Postulated Data For the SPUTTERED Pd-Ag ALLOY

\begin{tabular}{c|c|c|c}
\hline Material & $\begin{array}{c}\sigma_{\text {yield }} \\
(\mathrm{MPa})\end{array}$ & $\begin{array}{c}\mathrm{E} \\
(\mathrm{GPa})\end{array}$ & $\begin{array}{c}\sigma_{\text {ultimate }} \\
(\mathrm{Mpa})\end{array}$ \\
\hline Pd & $35-205$ & 121 & $175-325$ \\
\hline $\mathrm{Ag}$ & $172-330$ & 83 & $172-330$ \\
\hline $\mathrm{Pd}-\mathrm{Ag}$ & $80^{*}$ & $150^{*}$ & Non estimate \\
\hline
\end{tabular}

* Postulated data for the sputtered Pd-Ag in this work

for the deposited Pd-Ag alloy film. Applying (2) for a single 1 $\mu \mathrm{m}$ thick $\mathrm{Pd}-\mathrm{Ag}$ membrane spanning across a $28 \mu \mathrm{m}$ wide slit, we find a $P_{\max }$ of 4.1 bars.

The rupture strength $P_{\text {break }}$ of the $\mathrm{Pd}-\mathrm{Ag}$ membrane was measured at room temperature in the setup described by van Rijn et al. [27]. It was found that the Pd-Ag membranes did not break at a pressure difference of 4 bars over the membrane, but some of the membranes broke at a pressure difference of about 5 bars. Tests at higher pressure could not be carried out with the setup used. Nevertheless, as was expected, the membranes that broke ruptured on the $\mathrm{Pd}-\mathrm{Ag}$ membranes and not on the silicon support. Although the rupture strength of the membranes was not measured at higher temperatures, the room temperature tests show that the microfabricated membrane is mechanically strong enough to operate under the desired pressure gradient.

\section{Hydrogen Permeation and Selectivity of the Membranes}

To determine the hydrogen permeation and selectivity of the membranes, they were positioned in the previously described stainless steel membrane holder and heated up to the desired temperature. Membrane permeabilities and selectivities for hydrogen were determined as a function of hydrogen partial pressure $(0-0.3$ bars $)$ and temperature $\left(350-450{ }^{\circ} \mathrm{C}\right)$.

Although the mechanical strength tests at room temperature have shown that the membranes can withstand a pressure of at least 4 bars, up to this point no experiments had been carried out at high temperatures in the presence of hydrogen gas. It has to be taken into account that under such conditions the yield strength of the $\mathrm{Pd}-\mathrm{Ag}$ film may be completely different and perhaps drops to lower values. In addition, the yield strength of the materials may decrease after repetitive loading cycles. Therefore, for safety reasons the membranes were only tested at hydrogen pressures of up to 0.3 bars.

During these experiments the retentate and permeate sides of the membrane were continuously flushed at atmospheric pressure, the retentate side with a mixture of hydrogen and helium, the permeate side with pure nitrogen. The flux and selectivity were determined by measuring the hydrogen and helium concentration in the nitrogen stream with a gas chromatograph, equipped with a thermal conductivity detector (TCD). Details of the measurement set-up have been reported by Gielens et al. [31].

The hydrogen flow rate through the membrane versus the duration of the experiment is given in Fig. 11. It should be noted 
TABLE II

Comparison of the Permeation Result to the Literature Data of Thin SPuttered Pd- And Pd-Alloy Membranes on Porous Substrates

\begin{tabular}{|c|c|c|c|c|c|c|}
\hline \multirow[t]{2}{*}{ Membrane } & \multirow[t]{2}{*}{$\begin{array}{l}\text { Thickness } \\
(\mu \mathrm{m})\end{array}$} & \multirow{2}{*}{$\begin{array}{c}\text { Measuring } \\
\text { temperature } \\
\left({ }^{\circ} \mathrm{C}\right)\end{array}$} & \multirow{2}{*}{$\begin{array}{c}\text { Driving } \\
\text { force } \\
\Delta P\left(\mathrm{H}_{2}\right) \\
\text { ( Bar) }\end{array}$} & \multirow[t]{2}{*}{$\underset{\left(\mathrm{mol} . \mathrm{H}_{2} / \mathrm{m}^{2} . \mathrm{s}\right)}{\text { Flux }}$} & Selectivity & \multirow[t]{2}{*}{ References } \\
\hline & & & & & $\mathrm{H}_{2} / \mathrm{N}_{2}$ or $\mathrm{H}_{2} / \mathrm{He}$ & \\
\hline $\mathrm{Pd}-\mathrm{Ag} / \gamma-\mathrm{Al}_{2} \mathrm{O}_{3}$ & 0.35 & 250 & 1 & 0.015 & $5.7 *$ & {$[11]$} \\
\hline Pd- $\mathrm{Ag} / \gamma-\mathrm{Al}_{2} \mathrm{O}_{3}$ & $0.16-0.52$ & 300 & Not given & 0.01 & Up to $116^{* *}$ & {$[12]$} \\
\hline $\begin{array}{c}\mathrm{Pd} \text { and } \mathrm{Pd}-\mathrm{Ag} / \\
\gamma-\alpha \mathrm{Al}_{2} \mathrm{O}_{3}\end{array}$ & $0.1-1.5$ & 300 & 1 & $0.01-0.02$ & $30-200$ & [18] \\
\hline $\mathrm{Pd}-\mathrm{Ag} / \alpha-\mathrm{Al}_{2} \mathrm{O}_{3}$ & $0.7-1.1$ & 350 & $2-5$ & 0.05 & $4-80^{*}$ & [31] \\
\hline Pd-Ru-In/SS & 1.5 & 370 & 1 & 0.03 & Infinite & {$[32]$} \\
\hline $\mathrm{Pd}-\mathrm{Ag}$ & 1 & 450 & 0.3 & $0.15-0.5$ & Minimal of 550 & This work \\
\hline
\end{tabular}

* Selectivity for $\mathrm{H}_{2} / \mathrm{N}_{2}$

** Only one membrane had an exceptional selectivity of 3845

SS: stainless steel

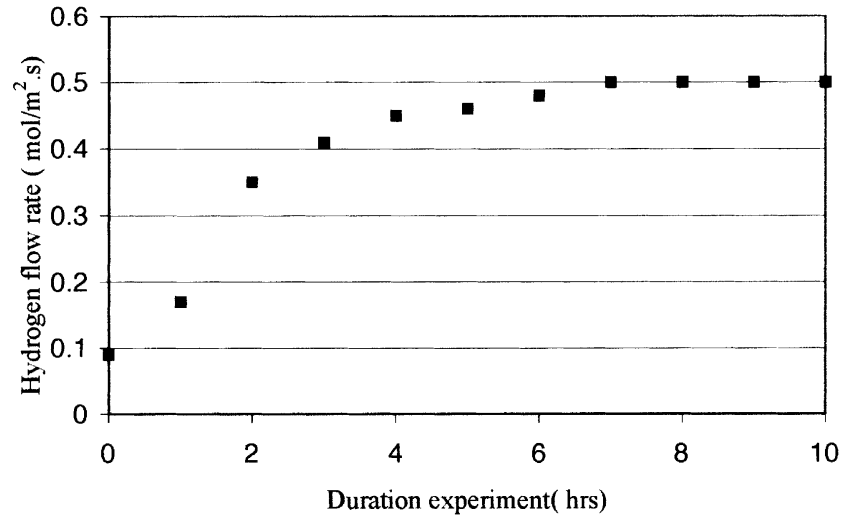

Fig. 11. Hydrogen flow rate through the membrane as a function of time at temperature of $450{ }^{\circ} \mathrm{C}$. The measurement started, when the membrane temperature was at $350^{\circ} \mathrm{C}$ in hydrogen environment.

that the measurement started when the membrane temperature was $350{ }^{\circ} \mathrm{C}$. At a membrane temperature of $450{ }^{\circ} \mathrm{C}$ and a hydrogen partial pressure of 0.2 bar at the retentate side, a hydrogen flux of $0.5 \mathrm{~mol} \mathrm{H} / 2 / \mathrm{m}^{2}$.s was achieved. Testing the membranes at higher hydrogen pressure will probably give higher hydrogen fluxes through the membranes, this will be carried out in a next study.

The dependence of hydrogen flux on temperature was also investigated. Fig. 12 shows the hydrogen flow rates through the membrane at different temperatures from $350{ }^{\circ} \mathrm{C}$ to $450{ }^{\circ} \mathrm{C}$. It can be seen that the hydrogen flow rate increases with increasing

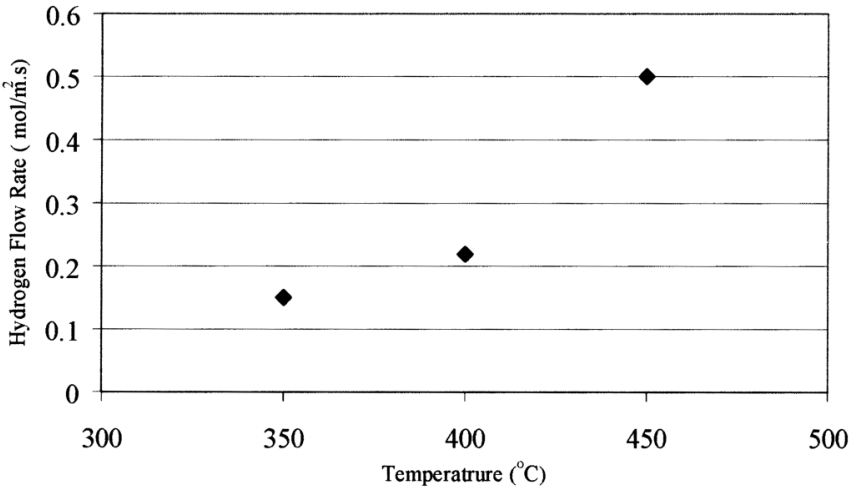

Fig. 12. Dependence of hydrogen flow rate through the microfabricated $\mathrm{Pd}-\mathrm{Ag}$ membrane on temperature.

temperature, however, the dependence is larger than expected from theory [32]. More experiments are currently being carried out in our laboratory to elucidate this effect and have a better understanding of membrane performance. Nevertheless it can be said that in the temperature range considered here the obtained fluxes are high in comparison with reported values for thin sputter-deposited $\mathrm{Pd}-\mathrm{Ag}$ membranes on porous substrates (see Table II).

For each of the samples that were investigated, we measured the helium concentration at the permeate side during the permeation experiment. A significant helium concentration would indicate a leak or pin-holes in the $\mathrm{Pd}-\mathrm{Ag}$ membranes, but in none 
of the cases helium was detected. Based on the helium detection limit of the gas chromatograph, a minimal separation selectivity of 550 for hydrogen to helium can be calculated. This selectivity is relatively high in comparison with that of conventional membranes fabricated by sputtering $\mathrm{Pd}-\mathrm{Ag}$ on porous substrates (see Table II). The measurements thus indicate that the micromachined $\mathrm{Pd}-\mathrm{Ag}$ membranes are virtually pin-hole free.

\section{CONCLUSION}

Wafer-scale $\mathrm{Pd}-\mathrm{Ag}$ alloy membrane modules were micromachined and tested. KOH etching of $\langle 110\rangle$-Si was utilized to fabricate a supporting structure for a sputtered $\mathrm{Pd}-\mathrm{Ag}$ film. This micron thick Pd-Ag layer was deposited by co-sputtering, which is a powerful method to make thin alloy film with highly homogeneous compositions. Anodic bonding of thick glass to silicon was used to package the membrane and create a robust module.

The membranes were found to have adequate mechanical strength and were capable of withstanding a pressure difference of 4 to 5 bars at room temperature. The microfabricated $\mathrm{Pd}-\mathrm{Ag}$ membranes obtained a high permeation rate and high selectivity for hydrogen. Typical flow rates of $0.5 \mathrm{~mol} \mathrm{H} / \mathrm{m}^{2}$. s were measured at the hydrogen pressure of 0.2 bars at $450^{\circ} \mathrm{C}$ with a minimal selectivity of 550 for $\mathrm{H}_{2}$ to $\mathrm{He}$.

The reported membranes may be applied for hydrogen separation or purification from gas mixtures or in membrane reactors for dehydrogenation. The results indicate that an industrial module that consists of a stack of a number of glass/membrane plates with a higher throughput of hydrogen is feasible.

\section{ACKNOWLEDGMENT}

The authors would like to thank the entire staff of the clean room facilities of the MESA + Research Institute, University of Twente, for technical support.

\section{REFERENCES}

[1] R. Ramachandran and R. K. Menon, "An overview of industrial uses of hydrogen," Int. J. Hydro. Energy, vol. 23, p. 593, 1998.

[2] R. Hughes, "Composite palladium membranes for catalytic membrane reactors," Memb. Tech., vol. 131, p. 9, 2001.

[3] T. N. Veziroglu, "Hydrogen energy system as a permanent solution to global energy-environment problems," Chem. Ind., vol. 53, p. 383, 1999.

[4] A. G. Knapton, "Palladium alloys for hydrogen diffusion membranes," Plat. Met. Rew., vol. 21, p. 44, 1977.

[5] A. C. Makrides, "Adsorption of hydrogen by Pd-Ag alloys," J. Phys. Chem., vol. 68, p. 2160, 1964.

[6] J. Shu, B. P. A. Grandjean, A. VanNeste, and J. Kaliaguine, "Catalytic palladium-based membrane reactors: Review," Can. J. Chem. Eng., vol. 69, p. 233, 1991.

[7] R. Dittmeyer, V. Hollein, and K. Daub, "Membrane reactors for hydrogenation and dehydrogenation processes based on supported palladium," J. Mol. Cat. A., vol. 173, p. 135, 2001.

[8] V. M. Gryaznov, "Hydrogen permeable palladium membrane catalysts. An aid to the efficient production of ultra pure chemical and phamarceuticals," Plat. Met. Rev., vol. 30, p. 68, 1986.

[9] R. Goto, "Purification of hydrogen by selective osmosis with palladium alloy membranes," KagaKu KogaKu, vol. 34, p. 381, 1970

[10] S. Tosti, L. Bettinali, S. Castelli, F. Sarto, S. Scaglione, and V. Violante, "Sputtered, electroless, and rolled palladium ceramic membranes," $J$. Membr. Sci., vol. 196, p. 241, 2002.
[11] V. Jayaraman and Y. S. Lin, "Synthesis and hydrogen permeation properties of ultrathin palladium-silver alloy membranes," J. Mem. Sci., vol. 104, p. 251, 1995.

[12] B. McCool, G. Xomeritakis, and Y. S. Lin, "Composition control and hydrogen permeation characteristics of sputter deposited palladium-silver membranes," J. Mem.Sci., vol. 161, p. 67, 1999.

[13] A. J. Frank, K. F. Jensen, and M. A. Schmidt, "Palladium based membranes for hydrogen separation and hydrogenation/dehydrogenation," in Proc. IEEE Conf. MEMS'99, 1999, p. 382.

[14] A. Zheng, F. Jones, J. Fang, and T. Cui, "Dehydrogenation of cyclohexane to benzene in a membrane microreactor," in Proc. of 4th Annual Conference on Microreaction Technology, 2000, p. 284.

[15] M. Elwenspoek and H. V. Jansen, Silicon Micromachining: Oxford Press, 1999.

[16] M. Vangbo and Y. Backlund, "Precise mask alignment to the crystallographic orientation of silicon wafers using wet anisotropic etching," $J$. Micromech. Microeng., vol. 6, p. 279, 1996.

[17] J. L. Vossen and W. Kern, Thin Film Processing II. New York: Academic, 1991.

[18] G. Xomeitakis and Y. S. Lin, "Fabrication of thin metallic membranes by MOCVD and sputtering," J. Mem. Sci., vol. 133, p. 217, 1996.

[19] H. D. Tong et al., "Characterization of the co-sputtering Pd-Ag alloy film," J. Mat. Sci. Lett., submitted for publication.

[20] R. C. Hughes, W. K. Schubert, T. E. Zipperian, J. L. Rodriguez, and T. A. Plut, "Thin films of $\mathrm{Pd} / \mathrm{Ni}$ alloys for detection of high hydrogen concentrations," J. Appl. Phys., vol. 62, p. 1074, 1987.

[21] H. Wensink, "Fabrication of Microstructures by Powder Blasting," Ph.D. dissertation, University of Twente, Enschede, The Netherlands, 2002.

[22] M. J. De Boer, J. G. E. Gardeniers, H. V. Jansen, M. J. Gilde, G. Roelofs, J. N. Sasserath, and M. C. Elwenspoek, "Guidelines for etching silicon MEMS structures using fluorine high density plasmas at cryogenic temperatures," J. Micromech. Syst., vol. 11, p. 385, 2002.

[23] D. L. Kendall, "Vertical etching of silicon at very high aspect ratios," Rev. Instr. Sci., vol. 9, p. 373, 1979.

[24] S. Kuiper, "Development and Application of Microsieves," Ph.D. dissertation, University of Twente, Enschede, The Netherlands, 2000.

[25] P. Krasuse, E. Oermeier, and W. Wehl, "Backshooter- a new smart micromachined single -chip inkjet printhead," in Proc.IEEE Conf. Transducer' 95 , p. 325 .

[26] A. Holke and H. T. Henderson, "Ultra-deep anisotropic etching of (110) silicon," J. Micromech. Microeng., vol. 9, p. 51, 1999.

[27] C. J. M. van Rijn, M. Wekken, W. Nijdam, and M. C. Elwenspoek, "Deflection and maximum load of microfiltration membrane sieves made with silicon micromachining," J. Micromech. Syst., vol. 6, p. 48, 1997.

[28] [Online]. Available: http://www.goodfellow.com

[29] F. C. Gielens, H. D. Tong, C. J. M. van Rijn, M. A. G. Vorstman, and J. T. F. Keurentjes, "High-flux palladium-silver alloy membranes fabricated by microsystem technology," Desalination, vol. 147, p. 417, 2002.

[30] T. L. Ward and T. Dao, "Model of hydrogen permeation behavior in palladium membranes," J. Mem. Sci., vol. 153, p. 211, 1999.

[31] J. O'Brien, R. Hughes, and J. Hisek, "Pd-Ag membranes on porous alumina substrates byunbalanced magnetron sputtering," Surf. Coat. Tech., vol. 142-144, p. 253, 2001.

[32] S. Yan, H. Maeda, K. Kusakabe, and S. Morooka, "Thin palladium membrane formed in support pores by metal-organic chemical vapor deposition method and application to hydrogen separation," Ind. Eng. Chem. Res., vol. 33, p. 616, 1994

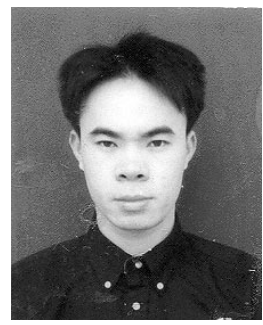

Hien Duy Tong received the M.Sc. degree in material science from the International Training Institute for Materials Science (ITIMS), Ha Noi University of University of Technology, Ha Noi, Vietnam, in 1995. His thesis dealt with a fabrication of pressure sensors by MEMS. After graduation, he worked as a Research Scientist at ITIMS. Since April 2000, he began working towards the Ph.D. degree in the Transducers Science and Technology group at MESA + Research Institute, University of Twente, The Netherlands.

His main research area is microfabrication of palladium-based membranes for hydrogen separation. 


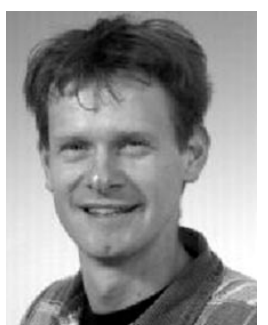

J. W. Erwin Berenschot was born on December 13, 1967, in Winterswijk, The Netherlands. He received the B.Sc. degree in applied physics from the Technische Hogeschool Enschede in 1990.

Since 1992, he is employed at the Transducers Science \& Technology group of the MESA + Research Institute. His main research area is fabrication technology with emphasis on development and characterization of etching and deposition techniques for the fabrication of microsystems.

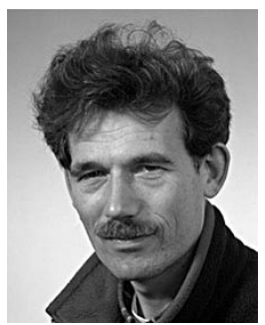

Meint J. de Boer joined the Company SENTRON in 1982. As a Process Engineer, he worked in the field of $\mathrm{pH}$-sensors and pressure sensors for medical applications. In 1988, he joined the University of Groningen at the Department of Applied Physics. $\mathrm{He}$ focused on nano-engineering for fundamental research on superconductivity. In 1992, he joined the Transducer Science Technology Group at the University of Twente, Enschede, The Netherlands. His current research interests include micromachining fabrication technology and dry etching techniques.

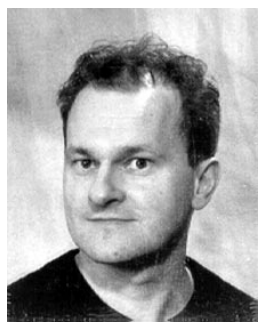

J. G .E. (Han) Gardeniers received the B.Sc., M.Sc., and Ph.D. degrees in 1982, 1985, and 1990.

He joined the Department of Electrical Engineering at the University of Twente, The Netherlands, as an Assistant Professor in 1990. After a short period as a Project Leader MEMS at Kymata Netherlands B.V. (currently: C2V B.V.) in 2001, he joined Micronit Microfluidics B.V. in September 2001, where he was responsible for R\&D related to miniaturized chemical synthesis and analysis systems. Since January 1, 2003, he has been an Associate Professor with the Department of Electrical Engineering, Mathematics and Informatics at the University of Twente, The Netherlands, within the Biosensors/Lab-on-a-Chip group. He has published over 50 reviewed journal papers on various topics in materials science, microfabrication, and microfluidics.

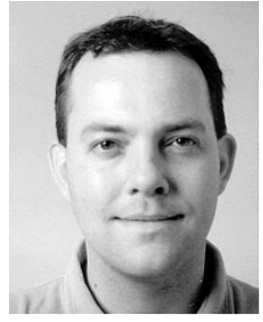

Henk Wensink was born in 1972 and received the M.Sc. and Ph.D. degrees in applied physics from the University of Twente, The Netherlands, in 1997 and 2002, respectively. His Ph.D. dissertation dealt with the fabrication of microstructures in glass and silicon by powder blasting.

In 2002, he joined the "Bios, lab-on-a-chip-group" of Professor A. van den Berg in the Department of Electrical Engineering at the University of Twente, Enschede, The Netherlands, working on Nuclear Magnetic Resonance (NMR) on chip for monitoring chemical reactions. His general research interests include micromachining fabrication technology and microfluidic systems.

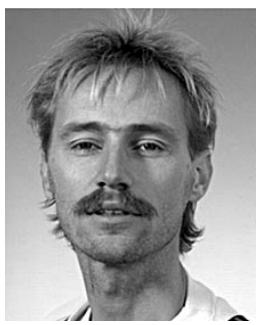

Henri V. Jansen received the M.Sc. degree in electronic engineering in 1991 and the Ph.D. degree in electronic engineering from the University of Twente, The Netherlands, in 1991 and 1996, respectively.

After working for half a year at CSEM in Neuchâtel, Switzerland, as a plasma engineer, he rejoined the Department of Electrical Engineering at the University of Twente, The Netherlands, as a Postdoctoral In 2000, he joined IMEC in Leuven, Belgium, to assist in the development of RF MEMS to be used in cellular phones. Since September 2001, he has been an Assistant Professor at the Department of Electrical Engineering at the University of Twente, The Netherlands. His main research expertise is in silicon-based micromachining in general and plasma engineering in particular, with applications in the field of miniaturized sensor and actuator systems.

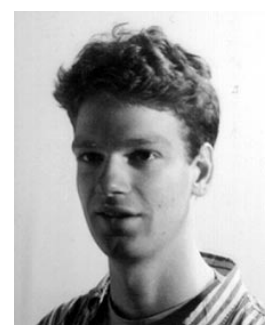

Wietze Nijdam received the M.Sc. degree in electrical engineering from the University of Twente, Enschede, The Netherlands, in 1995. His thesis dealt with a device for blood plasma separation.

After graduation, he started working as a Research Scientist at Aquamarijn Micro Filtration B.V. and he is involved in membrane fabrication.

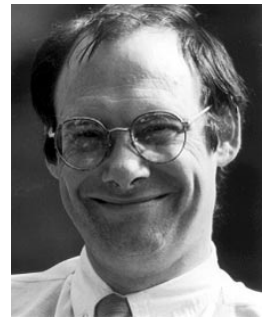

Miko C. Elwenspoek born December 9, 1948 in Eutin, Germany. He studied physics at the Free University of Berlin (West), Germany. His Master thesis dealt with Raleigh scattering from liquid glycerol using light coming from a Mössbauer source. From 1977 to 1979 he worked with Prof. Helfrich on lipid double layers. In 1979, he started working towards the Ph.D. degree with Prof. Quitmann on the subject: relaxation measurements on liquid metals and alloys, in particular alkali metal alloys. In 1983, he received the Ph.D. degree at the Freie Universität Berlin.

In the same year, he moved to Nijmegen, The Netherlands, to study crystal growth of organic crystals in the group of Prof. Bennema of the University of Nijmegen. In 1987 Miko went to the University of Twente, to take charge of the micromechanics group of the Sensors and Actuators lab, now called the MESA Research Institute. Since then his research focused on microelectromechanical systems, such as design and modeling of micropumps, resonant sensors and electrostatic microactuators for microrobots. Fabrication techniques such as the physical chemistry of wet chemical anisotropic etching, reactive ion etching, wafer bonding, chemical-mechanical polishing and the materials science of various thin films have his special attention. Since 1996, he has been employed as a Professor at the Transducer Technology group at the Faculty of Electrical engineering of the University of Twente.

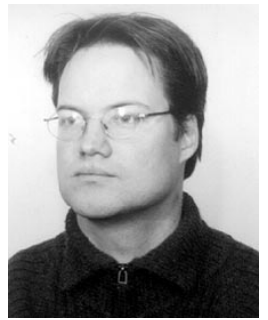

F. C. (Frank) Gielens was born on July 16, 1973, in Zaandam, The Netherlands. He received the M.Sc. degree in chemical engineering from the University of Amsterdam, The Netherlands, in 1996. From 1997 to 1999 , he followed a Post-Master Design course at the Technical University of Eindhoven and in 1999 he began working toward the Ph.D. degree in the Process Development group at the Technical University of Eindhoven.

His main research area is the characterization and application of hydrogen selective membranes, with emphasis on Pd alloy membranes fabricated with microsystem technology.

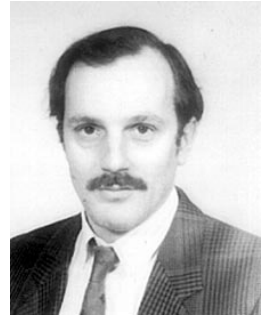

Cees J. M. van Rijn received the degree in physics from the Vrije Universiteit of Amsterdam, The Netherlands, in 1982. He received the Ph.D. degree in nuclear magnetic relaxation of polyelectrolyte solutions from the University of Leiden, The Netherlands, in 1986.

After graduation, he worked as Scientific Engineer at Philips Eindhoven, The Netherlands, and has special expertise in semiconductor technology, physical and chemical evaporation techniques, and wet and dry chemical etching. In 1993, he founded Aquamarijn Micro Filtration and he has performed research on microfiltration membranes at the MESA Research Institute, University of Twente, The Netherlands. 